\title{
Living with Juvenile Arthritis: A Parent's Guide
}

Kimberly Poston Miller. Ann Arbor: Spry Publishing LLC, 2013, 272 pages, \$17 US

Living with Juvenile Arthritis: A Parent's Guide is an easy-to-read book directed at parents of children with juvenile arthritis (JA) and related conditions. Written from the perspective of a mother of 2 children with JA, the book is well organized with stories, case examples, and practical tips and strategies, as well as highlighted sections that provide take-home messages for readers. The author's use of sports analogies (Miller is the wife of a former National Football League player) and her ease of writing make this an easily accessible read for parents at any stage of their child's disease course.

An important caution to readers is that the author presents a particular perspective. First, she has 2 children with JA, which is not typical. Second, 1 of her children has a unique and complex disease course that is not representative of the typical patient with JA.

While the Guide covers topics useful for all parents, the provided case examples are severe and could unnecessarily alarm parents of newly diagnosed children. The sections on how to communicate effectively with the healthcare team and how to find reliable information online are particularly helpful. It was good to see a section dedicated to self-care for parents where important insights are shared on the effects of parental attitude on child and family coping. The book ends on an encouraging note with a chapter about the positive effect families can have when they become involved in advocacy.

Although this is not a resource for parents looking for information on what to expect of their particular child's disease course, this book has a lot to offer. For parents looking for tips and strategies on how to cope with their child's JA, Miller has learned a lot from her own difficult journey.

NEELY LERMAN, MSW, RSW, Social Worker, Division of Rheumatology, The Hospital for Sick Children, Department of Social Work,

555 University Ave., Toronto, Ontario M5G 1X8, Canada.

E-mail: neely.lerman@sickkids.ca

J Rheumatol 2014;41:11; doi:10.3899/jrheum.140629 